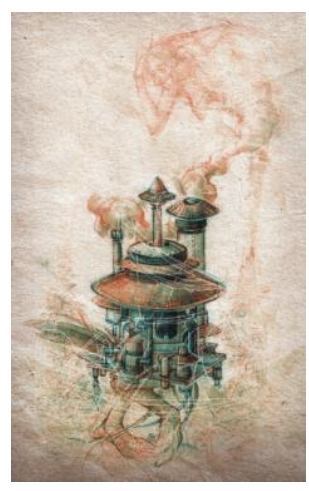

DOSSIÊ: $2^{\circ}$ Congresso de História da Ciência e da Técnica

\title{
A Ciência da História como Ciência das Leis:
}

\section{Uma leitura viquiana}

\author{
Ivan Leski \\ Doutor em História Social \\ Universidade de São Paulo - USP
}

Como citar este artigo: LESKI, Ivan "A Ciência da História como Ciência das Leis: Uma leitura viquiana”, Intelligere, Revista de História Intelectual, nº7, p. 238-246. 2019. Disponível em <http://revistas.usp.br/revistaintelligere>. Acesso $\mathrm{em} \mathrm{dd} / \mathrm{mm} /$ aaaa.

Resumo: Em seu livro Scienza Nuova (1744) Giambattista Vico considera o desenvolvimento das leis através da História como a manifestação mais confiável dos estágios do progresso humano. Este artigo procura explicar como e por que as leis mudam em épocas diferentes da história humana, em consonância com a concepção viquiana da História.

Palavras-chave: Vico, Ciência da História, Ciência das Leis, Progresso Humano, Mitologia

\section{Science of History as science of laws: a reading on Vico}

Abstract: Giambattista Vico, in his book Scienza Nuova (1744), considers the development of the human laws throughout History the most reliable manifestation of the human progress phases. This article tries to explain how and why laws change in different ages of human history, using Vico's ideas about History.

Keywords: Vico, Science of History, Science of Laws, Human Progress, Mithology

Em seu livro Princípios de uma Nova Ciência em torno da natureza comum das nações, publicado postumamente em 1744, o filósofo italiano Giambattista Vico (1668-1744) nos oferece uma visão renovadora da História que continua instigante até os dias atuais. Ao contrário da maioria dos pensadores do início do século XVIII, que influenciados pelo pensamento cientificista do século XVII cultivavam diversos graus de ateísmo, Vico era um 
católico devoto. Sua crença na Providência Divina levou-o a refletir sobre a maneira pela qual Deus, como criador do Homem, interfere na trajetória da Humanidade através dos tempos. A nova ciência proposta por Vico em seu livro mais conhecido procurava estabelecer leis gerais que explicassem o desenvolvimento dos povos de maneira a elaborar um padrão científico que permitisse uma observação mais precisa do que aquela oferecida pelos que se dedicavam à escrita da História na primeira metade do século XVIII. Posicionando-se contra uma matriz cartesiana e racionalista de pensamento, que via a História como uma disciplina não científica, ou seja, incapaz de produzir um conhecimento aferível por regras claras e imutáveis, Vico concebeu uma "bistória ideal eterna", pela qual passam todas as nações (Vico, 2010, "Ideia da Obra"). No entendimento do filósofo de Nápoles, Deus estabeleceu um conjunto de leis eternas que orientam o processo civilizatório dos povos, dos mais brutos aos mais intelectualmente sofisticados. Acreditamos poder aclarar a interpretação do progresso das leis examinando alguns dos conceitos desenvolvidos por Vico em sua obra aqui evocada.

Quando nós refletimos sobre a História como uma narrativa da existência dos povos através dos tempos, devemos voltar nossa atenção para as relações que se estabelecem entre indivíduos dentro de um espaço físico (Romagnosi, 1832, p. 12). O desenvolvimento de uma civilização, ou seja, a capacidade de grupos humanos unidos por afinidades linguísticas e necessidades comuns de construírem de maneira efetiva uma trajetória de vida, na maioria das vezes depende das formas utilizadas individualmente ou coletivamente para explorar os recursos naturais que estão à disposição. Mas qualquer que seja a atividade humana ela está circunscrita a um território determinado, cuja ocupação demanda o desenvolvimento de formas apropriadas de convivência com o meio ambiente, isto é, com o clima, a flora e a fauna.

Assim sendo, a maneira de arar os campos ou de pastorear rebanhos; as formas de comércio; a construção de moradias; a destreza com as armas; a implementação de técnicas de irrigação e de armazenamento; a produção de conhecimento sobre si mesmo e sobre o mundo que o cerca são fundamentais para o estabelecimento de bases seguras para o desenvolvimento de uma sociedade. Porém todas essas práticas vitais para o progresso de um povo, 
muito embora tenham uma origem individual (na medida em que um indivíduo ou um grupo de pessoas primeiramente as utilizaram), só podem ser colocadas efetivamente em uso através de um processo coletivo (Romagnosi, 1832, p. 24). Destarte é a associação dos indivíduos e sua capacidade de transmissão de experiências úteis à vida de sua comunidade de uma geração para outra que determinam o progresso de um povo dentro de um território.

O ordenamento jurídico, isto é, as normas de convivência que estruturam a vida cotidiana das comunidades, é um reflexo da maneira como os indivíduos a ele sujeitos interagem nos diversos níveis de sua socialização (Ambrosini, 1988, passim). Por isso não é de todo errado argumentar que as leis de um povo espelham a sua visão do mundo que o cerca. Daí acreditarmos que o progresso humano, no sentido de uma sofisticação das formas de convivência e de integração com o ambiente ao redor, se manifeste nas leis: quanto mais civilizado é um povo, mais brando e sofisticado seria o seu aparato jurídico. Em sua investigação sobre o progresso civilizatório dos povos, o jurista italiano Gian Domenico Romagnosi (1761-1835) nos diz " $a$ barbárie na verdade não se confunde com a maldade nem com um estado tigresco [sic], mas consiste sim na falta de uma culta e satisfatória convivência" (Romagnosi, 1832, p. 20, nossa tradução). Podemos inferir então que as leis, ao estabelecerem regras para legitimar os atos e as transações da vida cotidiana, são uma expressão do progresso mental e cultural dos povos através dos tempos.

Nos primórdios da História, quando os homens estavam mais perto da Natureza e dela dependia a sua sobrevivência, eles eram impotentes frente às catástrofes naturais: secas, pragas, incêndios e sabe-se lá o que mais lhes atingisse. Eles acreditavam então necessitar, para se defender dos infortúnios da Vida, da proteção de entidades a eles superiores: os deuses. Nessa época a principal preocupação de reis, sacerdotes, guerreiros, comerciantes, camponeses e escravos era não ofender os deuses. Eles escrutinavam os desejos divinos, seguiam suas leis e puniam, ou eram punidos, de acordo com a vontade dos imortais. Por isso essa foi chamada a Idade dos Deuses. No parágrafo 925 da Ciência Nova Vico afirma que os primeiros governos “foram divinos que os gregos diriam 'teocráticos' nos quais os homens acreditavam que tudo era comandado pelos deuses." 
$\mathrm{Na}$ Idade dos Deuses prosperou a história poética. Os fatos históricos, uma vez que não havia escrita, foram narrados poeticamente através dos mitos e das fábulas transmitidos oralmente aos homens pelos poetas teólogos, conforme explicado por Vico no parágrafo 916 da Ciência Nova. Segundo ele, os poetas teólogos "foram os mais antigos sábios de todas as nações gentílicas quando todas essas nações se fundaram sobre a crença, cada qual com a sua, de certos deuses próprios." À guisa de esclarecimento diríamos que o Mito é a narrativa histórica do governo dos deuses sobre os homens. As leis divinas são inapeláveis, mas precisam ser interpretadas porque os imortais possuem uma língua diferente daquela usada pelos homens. Segundo Vico essa língua dos deuses seria "mental por atos mudos religiosos" (Ciência Nova, 『929), cabendo a quem a domina interpretá-la para os demais: eis portanto a utilidade dos oráculos e dos sacerdotes.

Vejamos alguns exemplos. Édipo era rei de Tebas quando uma peste devastou a cidade. Convencido de que a praga era um castigo dos deuses por algum crime cometido pelos cidadãos ele envia seu cunhado Creonte a Delfos para interrogar o oráculo de Apolo. O deus faz saber a Édipo que Tebas só ficará livre da epidemia quando executar o assassino de seu antecessor, o rei Laio, morto misteriosamente muitos anos antes. Édipo então conduz uma rigorosa investigação que sabemos o aponta como o regicida cuja punição é demandada pelos deuses. Na tradição judaico-cristã Deus entrega a Moisés as tábuas onde Ele próprio escreveu os dez mandamentos que constituem a Sua lei. Também na Bíblia existem os profetas, tais como Jonas e Natã, pessoas comuns a quem Deus encarrega de transmitir a Sua vontade ao Seu povo, não raramente anunciando castigos por transgressões à Sua lei.

O desenvolvimento das formas de plantio e da criação de rebanhos, assim como a abertura de rotas comerciais terrestres e marítimas, muitas vezes como resultado de guerras e de conquistas, levou à acumulação de riquezas. Os homens já não se sentiam seguros nos campos, junto às suas famílias, seus agregados e seus escravos. O número de cativos, e provavelmente de revoltas, crescia na medida em que novas terras eram anexadas e seus habitantes subjugados. Os proprietários de terras decidiram, então, unir-se e fundaram as cidades. 
Nessa época os mais fortes, os mais adestrados militarmente, os que tinham mais capacidade de liderança se destacavam. Aqueles que conseguiam levar seus companheiros a superar as dificuldades inerentes à fundação de uma cidade eram por esses reconhecidos como homens superiores, seres humanos que possuíam qualidades pertencentes apenas aos deuses: esses homens eram heróis. De acordo com Vico, "se acrediton que eram os heróis de origem divina" (Ciência Nova \$917), o que os transformava em grandes líderes, capazes de conduzir seus povos a feitos notáveis. É como se pudéssemos entender que tais homens legavam a seus descendentes um poder inconteste, pois sua autoridade estava para sempre amparada e justificada em sua ascendência divina, que os colocava além da compreensão e do julgamento dos homens.

Hércules, Aquiles, Eneias, Rômulo são exemplos de filhos de deuses com mortais. Muitas cidades do Mediterrâneo antigo proclamavam terem sido fundadas por heróis: Atenas, Tebas, Esparta, Roma, Cartago para citar algumas (Ciência Nova, \$561). Uma vez reunidos em cidades, protegidos por muralhas e com guerreiros ousados para defendê-los, os homens deixam de viver na Idade dos Deuses e passam a viver na Idade dos Heróis.

Os heróis precisavam estabelecer regras que harmonizassem seus interesses conflitantes. Surgem assim os senados heroicos. Vico nos diz, no parágrafo 944 da Ciência Nova, "nas aristocracias heroicas, onde os senados se compuseram, (...) tal autoridade foi desses senados reinantes". Seria razoável supor que as leis das cidades heroicas eram impostas e mantidas pelos heróis e suas armas. Eles tinham poder de vida e morte sobre seus familiares, seus agregados e seus escravos. Ninguém podia se opor à sua vontade, e se um de seus pares se lhe opunha isso significava guerra. Nas palavras de Vico, "tal direito da força éo de Aquiles que põe toda a rą̧ão na ponta da lança" (Ciência Nova, §923). Os heróis, que se consideravam filhos de deuses e portanto com ascendência divina, eram arrogantes, violentos e arbitrários. Eles viviam de acordo com um código de honra e faziam de sua palavra a lei. A expressão máxima do direito heroico era o duelo: o litígio era resolvido por dois guerreiros em um combate de vida ou morte. Segundo Vico, a introdução dos duelos aconteceu "por falta de leis judiciárias" (\$961), uma vez que os costumes heroicos "foram coléricos e obstinados como são os narrados de Aquiles", conforme podemos ler no parágrafo 920 da Ciência Nova. 
A revolta dos fâmulos pôs fim ao governo dos heróis. Nas cidades heroicas os habitantes eram os heróis e suas famílias, sendo permitida a presença apenas dos servidores domésticos e de escravos que executavam tarefas dentro das casas. A plebe habitava os campos que eram arrendados pelos heróis. Mas somente estes podiam celebrar seus matrimônios e com isso legar seu patrimônio a filhos legítimos. Como os plebeus não tinham suas famílias juridicamente reconhecidas não podiam ter herdeiros. Assim, quando um chefe de família plebeu morria suas posses viravam propriedade do herói de quem ele era vassalo. Da mesma forma, quando falecia um suserano seu sucessor legal não era responsável pelo pacto do falecido com seus agregados, uma vez que a palavra de um não era a palavra do outro. Na Idade dos Heróis, de acordo com Vico, "a plebe era efetivamente excluida de tratar coisas públicas" (Ciência Nova, \$949) e por isso, podemos inferir, não tinha como expressar suas necessidades e seus anseios.

Os fâmulos se revoltaram para exigir dos heróis três coisas: em primeiro lugar que os plebeus pudessem contrair matrimônios e estruturar juridicamente suas famílias, legando suas posses a seus descendentes, legalmente constituídos; que as famílias plebeias pudessem viver dentro dos muros das cidades, protegendo assim suas mulheres e seus filhos; e finalmente que as leis fossem escritas (Romagnosi, 1832, p. 93, nota), livrando-os dos arbítrios praticados pelos heróis.

No momento em que os fâmulos conseguem impor aos senhores o aceite a essas reinvindicações acaba a Idade dos Heróis e inicia-se a Idade dos Homens. A partir de então as leis são escritas e valem para todos os cidadãos da cidade. Não para todos os habitantes porque frequentemente eram delas excluídos os escravos e os estrangeiros. Nessa época, segundo Vico, "todos se igualam com as leis, pois que todos nasceram livres nas suas cidades (...)" (Ciência Nova, \$927). Acrescentaríamos que nesse estágio surgem os legisladores, tais como Sólon em Atenas e Licurgo em Esparta. A legislação também passa a ser conhecida, uma vez que ela é compilada como, por exemplo, o Código de Hamurabi e a Lei das Doze Tábuas.

$\mathrm{Na}$ Idade dos Homens, explica Vico, "devem os povos livres ser senhores de suas leis" (Ciência Nova, \$936), e por isso essas leis eram, em sua maioria, consuetudinárias, ou seja, fundadas nos costumes (Scherillo, 1933). Seria 
razoável supor que nessa época surgem os historiadores, tais como Tito Lívio e Tácito, cujas obras fornecem subsídios aos legisladores. Também é possível inferir que um subproduto dessa era foram os arautos: como todos os cidadãos tinham adquirido o direito de conhecer as leis, mas a grande maioria da população era analfabeta, as decisões dos governantes deviam ser oralmente lidas em praça pública para que delas todos tomassem ciência. Além disso, diríamos que na Idade dos Homens aparecem os viajantes, aqueles que se dedicam a visitar cidades pelo mundo afora para conhecer seus habitantes, seus costumes e suas leis. A essa tarefa consagrou-se Heródoto, conhecido como o Pai da História.

Por que podemos pensar a Ciência da História como a Ciência das Leis? Porque as leis são fruto de um determinado momento histórico. Elas espelham o nível de desenvolvimento cultural, econômico e político de uma sociedade. As leis são a expressão de uma personalidade coletiva: elas nos mostram como as pessoas organizam sua vida privada, seus negócios, quais são suas aspirações, seus temores e como uma aglomeração de indivíduos se estrutura para que esforços individuais gerem benefícios para todos dentro de uma perspectiva comum.

A originalidade e a importância da obra de Vico só foram reconhecidas após a Revolução Francesa, quando o direito dos povos passou a ser o mote das diversas rebeliões contra o absolutismo monárquico que se espalharam pela Europa nas primeiras décadas do século XIX. Foram as revoluções liberais da década de 1820 que impulsionaram novas formas de pensamento acerca das leis. Gian Domenico Romagnosi, em sua obra Dell'indole e dei fattori dell'incivilimento con esempio del suo risorgimento in Italia, publicada em Milão em 1832, afirma "toda a essência, toda a verdade positiva, todo fruto da civilidade consiste na convivência civil' (Romagnosi, 1832, p. 31, nossa tradução). É possível inferir que o renomado jurista aqui se refere às relações entre indivíduos de diferentes interesses em uma esfera do direito tanto público como privado. Assim sendo, as normas que porventura venham a regular tais relações serviriam, em nosso entendimento, como uma amostra do nível de desenvolvimento sócio-cultural alcançado por um estado. A abrangência dessas 
normas de convivência, transformados em leis pela sanção de uma autoridade constituída, estaria restrita ao território submetido a essa mesma autoridade. Portanto seria razoável supor que ao longo da História houve um processo assimétrico do desenvolvimento humano, uma vez que "a convivência civil" destacada por Romagnosi como "a essência" de tal processo jamais foi uniforme no Mundo ao longo dos tempos.

Muitos acreditam que quanto mais evoluída é uma sociedade, mais sofisticado é o seu ordenamento jurídico. Em outras palavras, quanto mais liberalizantes os costumes, mais permissivas as leis. $\mathrm{Na}$ verdade, não faltam exemplos históricos para embasar essa teoria. Porém, o contrário também é verificável: leis permissivas enfrentam fortes reações daqueles que nelas enxergam a degeneração e a decadência de um determinado povo, pois segundo Romagnosi, existe no interior de qualquer sociedade uma "tendência espontânea à dissolução do bom viver civie' (Romagnosi, 1832, p. 20, nossa tradução). Em nossa hipótese de interpretação revolucionários e reacionários giram a Roda dos Tempos, transformando as vanguardas de ontem nas retaguardas de amanhã. Esse é um movimento contínuo, que torna fascinante a jornada pelos caminhos da História.

\section{Referências Bibliográficas}

AMBROSINI, Giangiulio; 1988. "Dirito e Societa" in Romano, Ruggiero e Vivanti, Corrado. Storia d'Italia, volume primo, I caratteri originali. Torino: Giulio Einaudi Editore.

LESKI, Ivan; 2010. A Concepção de História em Giambattista Vico; dissertação de mestrado. São Paulo: Faculdade de Filosofia, Letras e Ciências Humanas da Universidade de São Paulo.

; 2015. "Giambattista Vico e a história da História" in Revista

Poder e Cultura, vol. 2, n. ${ }^{\circ} 4$.

ROMAGNOSI, Gian Domenico; 1832. Dell'indole e dei fattori dell'incivilimento con esempio del suo risorgimento in Italia. Milano: Società degli Editori degli Annali Universali delle Scienze e dell'Industria.

SCHERILLO, Gaetano; 1933. "Legge; storia" in Enciclopedia Italiana di Scienze, Lettere ed Arti, volume XX. Roma: Istituto della Enciclopedia Italiana. 
VICO, Giambattista; 2010. Ciência Nova; tradução de Wilma de Katinzky. São Paulo: Editora Hucitec. Riccardo Ricciardi Editore.

; 1953. Opere; a cura di Fausto Nicolini. Milano/Napoli: 